\title{
A measured risk approach to managing the design and operation of a tailings storage facility
}

\author{
JP Coffey Rio Tinto Iron Ore, Australia \\ JD Plunkett Rio Tinto Iron Ore, Australia
}

\begin{abstract}
Tailings storage facility (TSF) design has long been based on deterministic limits. By extension, the TSF owner accepts a Probability of Failure (PF) associated with these deterministic limits which are assessed against 'industry norms' with respect to investigation/analysis and design assumptions related to the operation of the facility. If the Probability of Failure of a design that is derived in this way is taken as the likelihood related to the tolerable risk limit, it follows that the same, or a lower PF, should be maintained during operations.

Examples of operational controls include pond management and inspections/monitoring. Upset conditions arise when operational controls are not being implemented. Therefore, by comparing the calculated PF of the TSF complying with the design assumptions and the PF for the same TSF in an upset condition, the required PF of operational controls can be estimated. This concept assists the TSF owner in determining what is required to safely operate the facility and communicate the geotechnical risk to all stakeholders. By extension, scenarios where a TSF owner cannot achieve the required PF of operational controls can be addressed with:
\end{abstract}

1. Greater rigor applied to operational controls.

2. Addition of more operational controls.

3. A change to the design assumptions, where the timing of the project allows.

This method provides a measured approach to risk management in the design and operational phases, without a TSF owner having to quantify an acceptable risk tolerance. Instead, the design is based upon widely accepted practice and industry/business accepted safety, economic and environmental risk levels. Subsequently, the design PF can be calculated and then applied as a benchmark for operations. This approach serves to reduce uncertainty through alignment of the design and operation phases.

The concept is explored for three different tailings storage methods: upstream raised TSF, downstream raised $T S F$, and impoundment by mine waste dumps, to estimate how sensitive each storage method is to the type and effectiveness of operational controls implemented by the dam owner.

Keywords: tailings storage facility, operation, Probability of Failure, control

\section{Introduction}

Tailings storage facilities (TSFs) are typically designed to meet prescriptive guidance. Consequently, designs that comply with current guidance documents define the tolerable risk for a given mine site or mining company. In addition, design is often completed without due consideration of the operator's ability to manage the facility. To further confound this, TSF reliability is considered flawless in planning, subsurface investigation, analysis and design, construction, operations and monitoring (Boshoff 2015). For example, a key question may be whether the owner wishes to spend time and effort tracking and maintaining the pond extent, or if they would spend more capital in the interest of achieving a more robust design where operation is simplified. If the owner accepts more influence on the Probability of Failure (PF) during operations, a TSF where the PF is sensitive to operational controls may be acceptable, which could potentially present opportunities to reduce capital expenditure. However, if the inverse is true, capital expenditure may be increased to realise the benefit of less onerous controls being required during operations. To further this 
example, the owner may consider if they have a higher level of confidence in an operational control (their ability to meet the obligations laid out in the operations, monitoring and maintenance manual) or design control (the ability and internal quality control processes of the designer). If the latter is true, increasing capital expenditure alone may reduce the risk profile of the TSF for the life of the facility.

As mentioned previously, the tolerable risk level is somewhat set in the design phase through compliance to a combination of regulatory conditions and 'industry norms' detailed in guidance documents published by government or industry bodies (e.g. the Australian National committee on Large Dams and the Mining Association of Canada). Although each component of the applicable requirements and guidance has been derived with rigor applied, there is no guarantee that a consistent risk profile will result for any two operating TSFs, as the likelihood and consequence of failure will be influenced by many independent variables. Although some owners may apply their own design criteria with a tolerable risk limit in mind, different construction methods and uncertainties (for example for material parameters and limitations of analysis methods) likely mean that a consistent risk profile is actually rarely met. As discussed above, this is then exacerbated by operations not complying with the controls that are assumed during design, or design not considering the 'worst case'. Even worse, is a situation where the owner has not quantified or does not understand the risk associated with the operation of the TSF and instead considers a TSF safe due to the 'engineering controls' incorporated within the design. As Bruce and Oboni (2002) point out, a risk assessment does not replace sound engineering or sound knowledgeable tailings management. However, it is a powerful complimentary tool that can assist to define the boundaries of the design analysis and determine the necessary operational controls, thus increasing the reliability of the facility.

The available industry guides do include some limited discussion on the selection of design inputs related to operations, although explicit recommendations are rare. The International Council on Mining and Metals (ICMM 2016) state that risk controls should be identified considering all phases and failure modes applicable for a facility and that each risk control should have established performance criteria. The Mining Association of Canada (2017) expands upon this approach by recommending performance objectives and indicators (detailed performance requirements arising from objectives) that are derived with consideration of design objectives and criteria, including geotechnical, geochemical, operational, community, and environmental performance objectives that the tailings facility is expected to achieve. With respect to operations of the TSF, it is stated that the owner should ensure tailings management complies with, among other things, the set design criteria.

Whilst the Australian National Council on Large Dams (2012) also eludes to the importance of the selection of design inputs related to operations in discussion of selection of loading conditions, physical conditions and scenarios, the proceeding discussion is focused only on the selection of shear strengths. Further, it is stated that situations which can lead to an overestimation of the Factor of Safety (FS) can usually be related to the assumptions made regarding shear strength and pore pressures. This is logical as the guide also recommends that the operations plan ensures that the TSF is operated in accordance with the design report. There are other guides available with similar commentary. A common theme is that the designer should select 'appropriate bounds' for the design analysis and then the owner/operator should operate the TSF in accordance with the design. Although this approach, in theory, means that the intended reliability of the structure should be achieved in operation, it assumes that the dam owner will ensure the operational constraints are implemented, with no consideration for the limitations that may be present on site. It must be stated that most design guidance relates to deterministic design approaches, and so overestimation of the FS and not an underestimation of the PF may have been the primary focus when they were developed. The alternative approach discussed in this paper is for the owner to have input at the design stage to ensure the operations plan is achievable and thus ensure the effectiveness of controls based on the any inherent constraints and their risk appetite. This appears to be an extension and not a modification to the guides discussed above.

A risk assessment could be applied to define the worst credible operating conditions and the subsequent impact to the PF of the TSF then proposed. Such an approach would assist in decision-making during the design phase and create well-understood and informed operating limits, and assist in reducing the risk 
associated with basing design assumptions on what is unknown at the time. This approach perhaps seems logical when it is considered that Failure modes and effects analysis (FMEA) and other qualitative risk assessment techniques are nothing more than organised judgement, common sense with a fancy name (Martin \& Davies 2002). Even if quantitative approaches are applied it must be remembered that these do not provide precise numbers and are less important than understanding and clearly documenting what the major risk contributors are (US Department of the Interior Bureau of Reclamation 2015), which should then form the basis for the determination of risk controls. Regardless of the exact method, it is also important that any risk-informed design approach must be applied by a management team that understands the design limitations and is committed to the safety and longevity of the design (Murray et al. 2010) with an understanding that all facilities carry some degree of risk, even after risk management plans have been implemented (International Committee on Large Dams 2001).

\section{Method}

In order to examine the impact of assumptions relating to operations on the reliability of different TSFs, the calculated FS and PF resulting from the assumptions adopted from the design and worst credible scenario are compared. The concept is illustrated in Figure 1 and Equations 1 to 5. A design that is sensitive to the reliability of operational controls is represented by a low required PF of operational controls from Equation 4 and, conversely, an insensitive design is represented by a high required PF of operational controls. In simple terms, if the design is sensitive the operator has relatively greater influence on the PF and more rigor will be needed to ensure safe TSF operation. Such an approach in practice may result from the pursuit of lowering capital expenditure or delivering a project on a tight schedule. In both cases, the owner should be aware of the trade-off being made with each decision in the design phase and understand the importance of prudent operations.
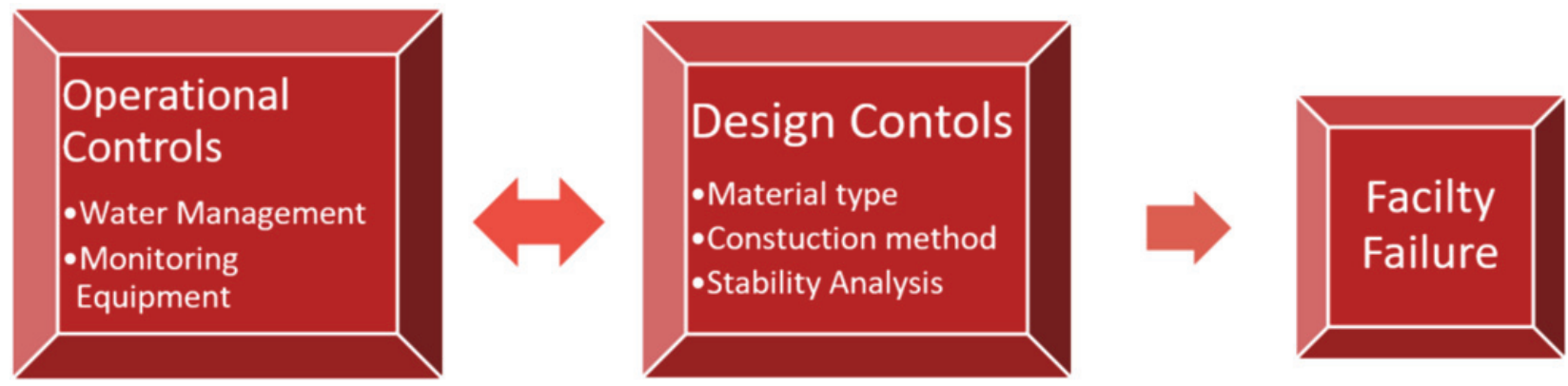

Assumed $\mathrm{PF}$ for design $\cdot \mathrm{PF}$ for design case $=\mathrm{PF}_{\mathrm{DESIGN}}$

$$
\text { Achieved PF of operation controls } \cdot \mathrm{PF} \text { for 'upset' condition }=\mathrm{PF}_{\text {Operation }}
$$

Figure 1 Illustration of the method used to calculate and compare the design and operational PF

The PF accepted with the design can be maintained in the operational phase by equating Equation 2 with Equation 1, such that:

$$
\mathrm{PF}_{\text {OPERATION }} \leq \mathrm{PF}_{\mathrm{DESIGN}}
$$

Substituting Equation 3 into Equation 2 and rearranging produces:

$$
\text { Minimum reliability of operational controls }=1-\frac{\mathrm{PF}_{\mathrm{DESIGN}}}{\mathrm{PF} \text { for 'upset' condition }}
$$

where:

$$
\text { Reliability }=1-\mathrm{PF}
$$

A required $\mathrm{PF}$ of operational controls is not able to be calculated in all cases, as three of the four example embankments have an FS and statistical distributions of critical material parameters such that no sample case resulted in an FS less than 1. In this case, the sensitivity of the FS is focused upon in the discussion. 
Consequences are not defined in the examples provided in this paper, but are critical for application of this process in practice. Rather, it is assumed that the consequence does not change between the design and operational phases of each TSF's life, which often may not be the reality. Also, the PF has not been calculated considering the likelihood that an upset condition arises, which should be included if the approach discussed in this paper were applied in practice. It is also important to note that the PF is simply the calculated likelihood that the calculated FS is less than one for the range of inputs, which does not guarantee that failure will occur. There are many good texts on probabilistic slope stability analysis, to which the reader is referred for further detail.

\section{$3 \quad$ Analysis}

The examples in this paper focus only on the static slope stability of four TSFs. It is acknowledged that this is an overly simplified assessment and other failure modes (e.g. overtopping and piping) may be more critical for the structures presented. However, for the TSFs examined in this paper an emergency spillway is present to prevent overtopping and piping is may not be critical for example 2 and 4 due to the zoning and width of the dams, respectively.

Probabilistic slope stability analysis was completed in Slide 7.0 (Rocscience Inc. 2017). Monte Carlo simulation was applied for sampling of the input parameters. The FS was estimated using the Morgenstern-Price method with non-circular failure surfaces. The auto refine search routine was used primarily, with validation completed with the path search and cuckoo search functions. This method implicitly assumes that all materials are perfectly plastic and therefore there is no analysis of post-yield behaviour in any of the following examples.

Material parameters were sourced from data detailing previous geotechnical investigations. Where any data was incomplete, engineering judgement was applied with some reference to Duncan (2000). Statistical distributions were assigned to materials which were subjectively assessed as potentially having a significant impact on embankment stability. Parameters were assumed to be normally distributed with the maximum and minimum values capped at three standard deviations from the mean value. This approach is aligned with approximate methods such as the three sigma rule discussed in Duncan (2000). However, as the distribution of shear strengths of each material is not proven by testing, which in itself would be a difficult task, the results are only approximate.

The inclusion of a loose contractive layer of tailings, that may have arisen due to poor control of the plant, deposition or decant earlier in the operation of the facility will be assessed on all four examples. To demonstrate the influence operational controls may have on the PF of each structure.

The maximum extent of the pond for each TSF was selected to represent an upset, but credible operating condition. Separate water balance calculations to further define the probability that the upset condition occurs, were not undertaken.

\subsection{Example 1: progressively upstream raised}

Example 1 is a hypothetical example of a progressively upstream raised TSF with a maximum height of $30 \mathrm{~m}$ and a 1 (vertical) to 4 (horizontal) downstream batter. It has an underdrain installed adjacent to the upstream toe of the starter embankment and minimum beach width of $100 \mathrm{~m}$ stated in its operations manual. It is assumed that poor pond management occurred shortly after the commissioning of the initial raise, which resulted in a $0.5 \mathrm{~m}$ deep loose and potentially contractive layer of tailings being present across the beach. Figure 2 presents the material properties and geometry of the model. The probabilistic inputs used in the model are shown in Table 1. 


\begin{tabular}{|c|c|c|c|c|c|c|c|c|c|}
\hline \multirow{2}{*}{ Material Name } & Color & $\begin{array}{c}\text { Unit Weight } \\
\mathbf{( k N / m 3 )}\end{array}$ & $\begin{array}{c}\text { Cohesion } \\
\mathbf{( k P a )}\end{array}$ & $\begin{array}{c}\text { Phi } \\
\mathbf{( d e g )}\end{array}$ & $\begin{array}{c}\text { Vertical } \\
\text { Strength } \\
\text { Ratio }\end{array}$ & $\begin{array}{c}\text { Minimum Shear } \\
\text { Strength (kPa) }\end{array}$ & KS (m/s) & K2/K1 & $\begin{array}{c}\text { K1 Angle } \\
\text { (deg) }\end{array}$ \\
\hline Earthfill & $\square$ & 22 & 0 & 34 & & & $1 \mathrm{e}-06$ & 1 & 0 \\
\hline Tailings & $\square$ & 16 & & & 0.3 & 10 & $1 \mathrm{e}-07$ & 1 & 0 \\
\hline Foundation & $\square$ & 18 & 5 & 28 & & & $1 \mathrm{e}-09$ & 1 & 0 \\
\hline Drain & $\square$ & 20 & 0 & 34 & & & 0.0001 & 1 & 0 \\
\hline Contractive Slimes & $\square$ & 16 & & & 0.07 & 0 & $1 \mathrm{e}-07$ & 1 & 0 \\
\hline Unsaturated Loose Tailings & $\square$ & 16 & 0 & 25 & & & $1 \mathrm{e}-07$ & 1 & 0 \\
\hline
\end{tabular}

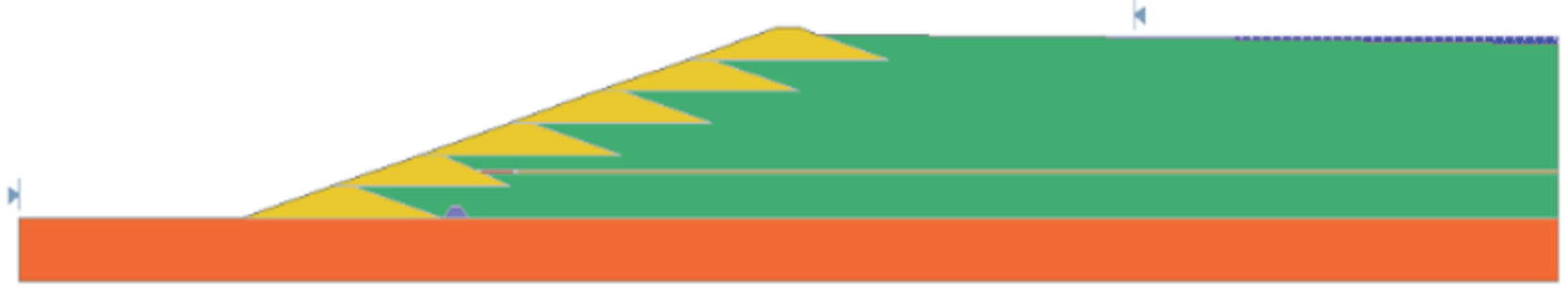

Figure 2 Example 1 geotechnical model and material types (vertical scale exaggerated)

Table 1 Probabilistic inputs for example 1

\begin{tabular}{lllll}
\hline Name & Property & Distribution & Mean & Std. dev. \\
\hline Earthfill & Phi & Normal & 34 & 4 \\
Tailings & Vertical stress ratio & Normal & 0.3 & 0.1 \\
Contractive slimes & Vertical stress ratio & Normal & 0.07 & 0.03 \\
Unsaturated loose tailings & Phi & Normal & 25 & 3 \\
\hline
\end{tabular}

The results of the analysis for example 1 are presented in Table 2, from which it is clear that the facility is sensitive to the position of the phreatic surface due to the contractive nature of the loose layer resulting from poor pond control shortly after the initial raise, which is supported by the nature of the critical failure surface shown in Figure 3.

Table 2 Results of analysis for example 1

\begin{tabular}{llll}
\hline Case & Description & FS & PF (\%) \\
\hline 1 & Design case; 100 m dry beach and operational underdrain & 1.49 & 9.3 \\
2 & Upset operational case; underdrain not operational & 1.33 & 18.6 \\
3 & Upset operational case; 50 m dry beach and operational underdrain & 1.01 & 42 \\
\hline
\end{tabular}




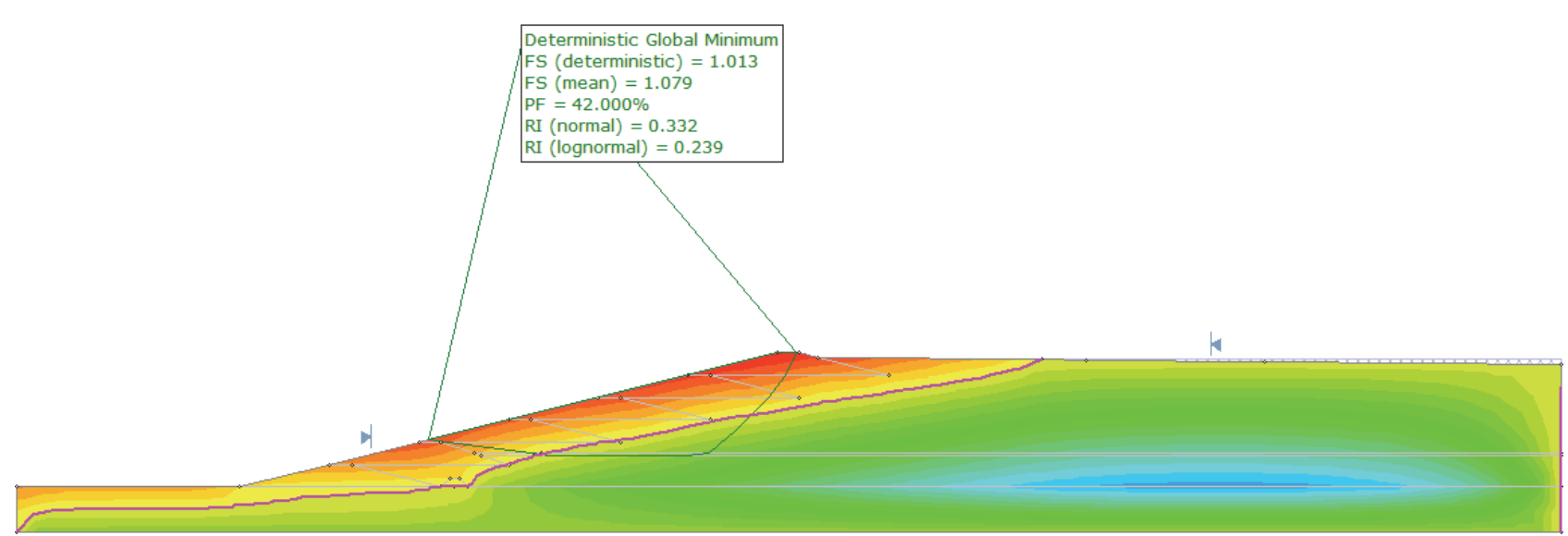

Figure 3 Case 3 stability plot showing significant influence of contractive tailings layer for the upset operational case with a $50 \mathrm{~m}$ dry beach

\subsection{Example 2: water-retaining starter dam with subsequent centreline raise}

The example 2 TSF was originally constructed as a water retention dam and, as such, had the supernatant pond against it for many years. Consequently, the initial inputs to the seepage modelling were selected to represent all tailings being saturated. A small centreline raise was added to the original dam, such that the maximum height is $38 \mathrm{~m}$ and the downstream batter varies between 1 (vertical) to 2.0 and 2.5 (horizontal). The material inputs and geometry of the model are shown in Figure 4. Probabilistic inputs are presented in Table 3. Two operational controls assumed in the design are tested; the presence of a $100 \mathrm{~m}$ dry beach and the operation (free-draining) of the downstream foundation filter blanket.

\begin{tabular}{|c|c|c|c|c|c|c|c|c|c|}
\hline Material Name & Color & $\begin{array}{c}\text { Unit Weight } \\
(\mathbf{k N} / \mathbf{m} 3)\end{array}$ & $\begin{array}{c}\text { Cohesion } \\
(\mathbf{k P a})\end{array}$ & $\begin{array}{c}\text { Phi } \\
(\mathbf{d e g})\end{array}$ & $\begin{array}{c}\text { Vertical } \\
\text { Strength } \\
\text { Ratio }\end{array}$ & $\begin{array}{c}\text { Minimum Shear } \\
\text { Strength (kPa) }\end{array}$ & KS (m/s) & K2/K1 & $\begin{array}{c}\text { K1 Angle } \\
\text { (deg) }\end{array}$ \\
\hline Zone A & $\square$ & 21.5 & 0 & 30 & & & $2 \mathrm{e}-09$ & 1 & 0 \\
\hline Zone B & $\square$ & 22 & 0 & 30 & & & $8 \mathrm{e}-09$ & 1 & 0 \\
\hline Filter Blanket & $\square$ & 20 & 0 & 35 & & & 0.0001 & 1 & 0 \\
\hline Foundation & $\square$ & 21.6 & 200 & 25 & & & $1 \mathrm{e}-06$ & 0.5 & 0 \\
\hline Zone 3A Rockfill & $\square$ & 23 & 0 & 40 & & & 0.01 & 1 & 0 \\
\hline Zone 1B & $\square$ & 22 & 0 & 30 & & & $8 \mathrm{e}-09$ & 1 & 0 \\
\hline Tailings Crust & $\square$ & 14 & & & 0.05 & 5 & $2 \mathrm{e}-08$ & 1 & 0 \\
\hline Tailings Upper Crust & $\square$ & 17 & & & 0.12 & 20 & $2 \mathrm{e}-08$ & 1 & 0 \\
\hline Tailings Soft & $\square$ & 14 & & & 0.1 & 8 & $2 \mathrm{e}-08$ & 1 & 0 \\
\hline
\end{tabular}

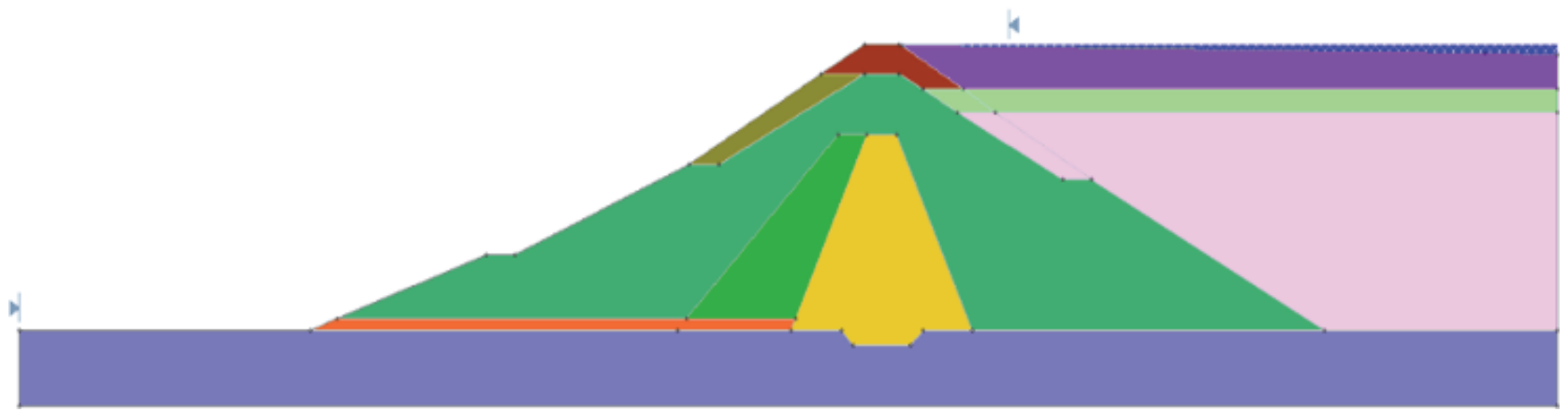

Figure 4 Example 2 geotechnical model and material types (vertical scale exaggerated) 
Table 3 Probabilistic inputs for Example 2

\begin{tabular}{lllll}
\hline Name & Property & Distribution & Mean & Std. dev. \\
\hline Zone A & Unsaturated shear strength & Normal & 32 & 5 \\
Zone B & Unsaturated shear strength & Normal & 32 & 5 \\
Filter blanket & Unsaturated shear strength & Normal & 37 & 5 \\
Zone B1 & Unsaturated shear strength & Normal & 32 & 5 \\
\hline
\end{tabular}

The results of the tested cases are presented in Table 4, which shows that the embankment stability is most sensitive to the operation of the downstream foundation filter blanket (a design control). The seepage and stability results for this case are presented in Figure 5, where the permeability of the filter blanket has been decreased to $1 \times 10^{-6}$ from the value shown in Figure 4, and lead to the filter blanket not being able to drawdown the phreatic surface prior to the downstream toe. However, in general, the stability of the embankment is relatively insensitive to operational performance.

Table 4 Results of analysis for example 2

\begin{tabular}{llll}
\hline Case & Description & FS & PF (\%) \\
\hline 1 & Design case; $100 \mathrm{~m}$ dry beach and operational foundation filter blanket & 2.01 & 0 \\
2 & Upset operational case; no dry beach and operational foundation filter blanket & 1.94 & 0 \\
3 & Upset operational case; no dry beach and inoperable foundation filter blanket & 1.38 & 0 \\
\hline
\end{tabular}

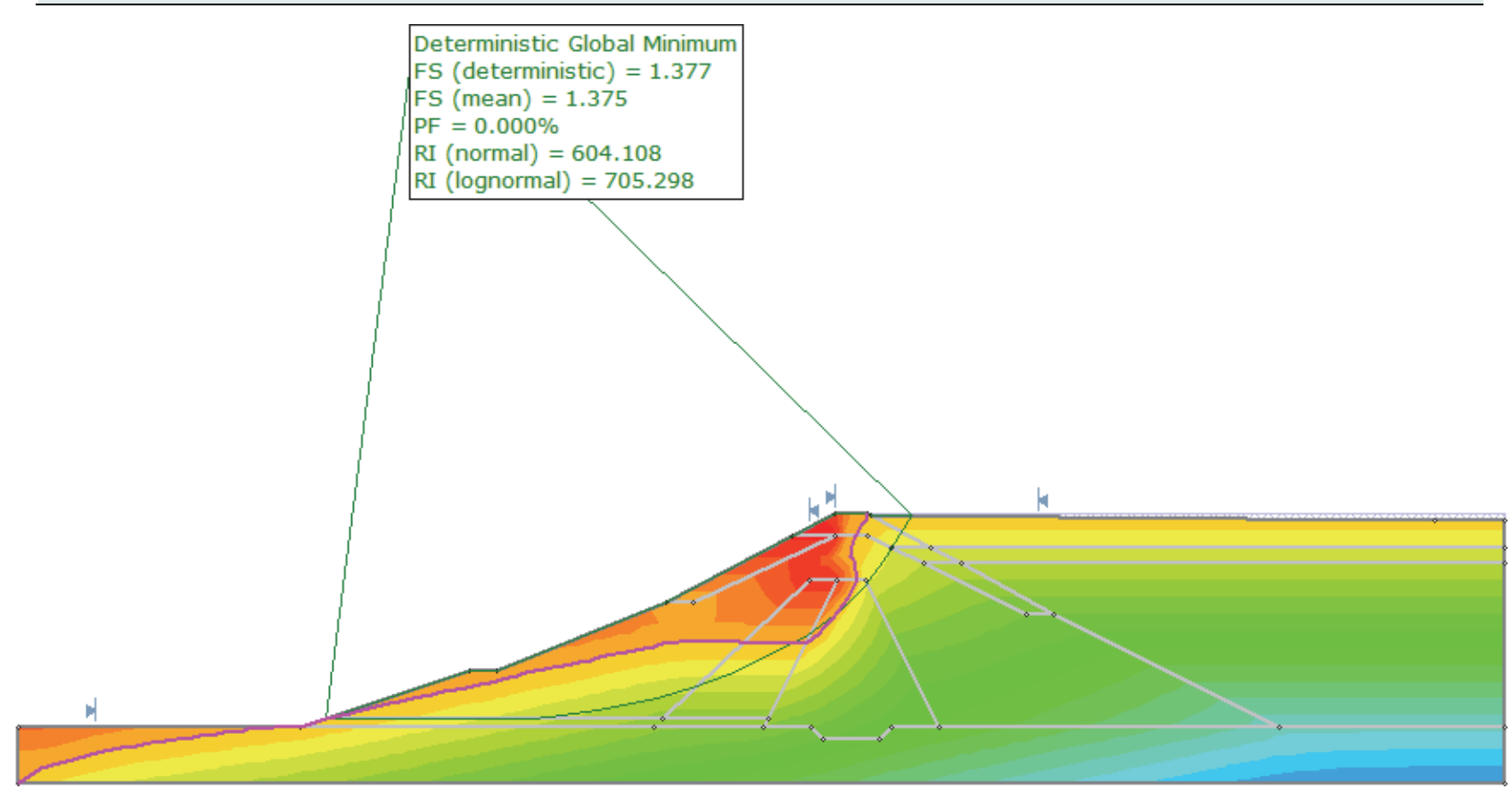

Figure 5 Example 2 seepage and stability analysis results with the foundation filter blanket clogged, making it inoperable

\subsection{Example 3: downstream raised TSF with low permeability upstream core}

Example 3 is a conventional progressively downstream raised TSF, where the initial low-permeability core was extended as an upstream lining during subsequent raises. The maximum height is $27.5 \mathrm{~m}$, and the downstream batter varies between 1 (vertical) to 1.75 and 2.5 (horizontal). The operational control tested 
was the compliance to a $50 \mathrm{~m}$ dry beach. The material inputs and geometry of the model are presented in Figure 6. The probabilistic inputs are presented in Table 5.

\begin{tabular}{|c|c|c|c|c|c|c|c|c|c|}
\hline \multirow[b]{2}{*}{ Material Name } & \multirow[b]{2}{*}{ Color } & \multirow[b]{2}{*}{$\begin{array}{l}\text { Unit Weight } \\
\text { (kN/m3) }\end{array}$} & \multirow[b]{2}{*}{$\begin{array}{c}\text { Cohesion } \\
\text { (kPa) }\end{array}$} & \multirow[b]{2}{*}{$\begin{array}{c}\text { Phi } \\
\text { (deg) }\end{array}$} & \multirow{2}{*}{$\begin{array}{c}\text { Vertical } \\
\text { Strength } \\
\text { Ratio }\end{array}$} & \multirow[b]{2}{*}{$\begin{array}{l}\text { Minimum Shear } \\
\text { Strength (kPa) }\end{array}$} & \multirow[b]{2}{*}{$\mathrm{KS}(\mathrm{m} / \mathrm{s})$} & \multirow[b]{2}{*}{ K2/K1 } & \multirow[b]{2}{*}{$\begin{array}{c}\text { K1 Angle } \\
\text { (deg) }\end{array}$} \\
\hline & & & & & & & & & \\
\hline Zone A & & 18 & 5 & 28 & & & $1 \mathrm{e}-08$ & 1 & 0 \\
\hline Zone C & & 20 & 0 & 32 & & & $1 e-07$ & 1 & 0 \\
\hline Tailings & [ & 15 & 0 & 15 & & & Se-08 & 1 & 0 \\
\hline Alluvium & L & 20 & 5 & 31 & & & $1 e-05$ & 1 & 0 \\
\hline Ferricrete & & 20 & 0 & 32 & & & $1 e-06$ & 1 & 0 \\
\hline Loose contractive tailings & & 15 & & & 0.07 & 0 & $1 e-07$ & 1 & 0 \\
\hline
\end{tabular}

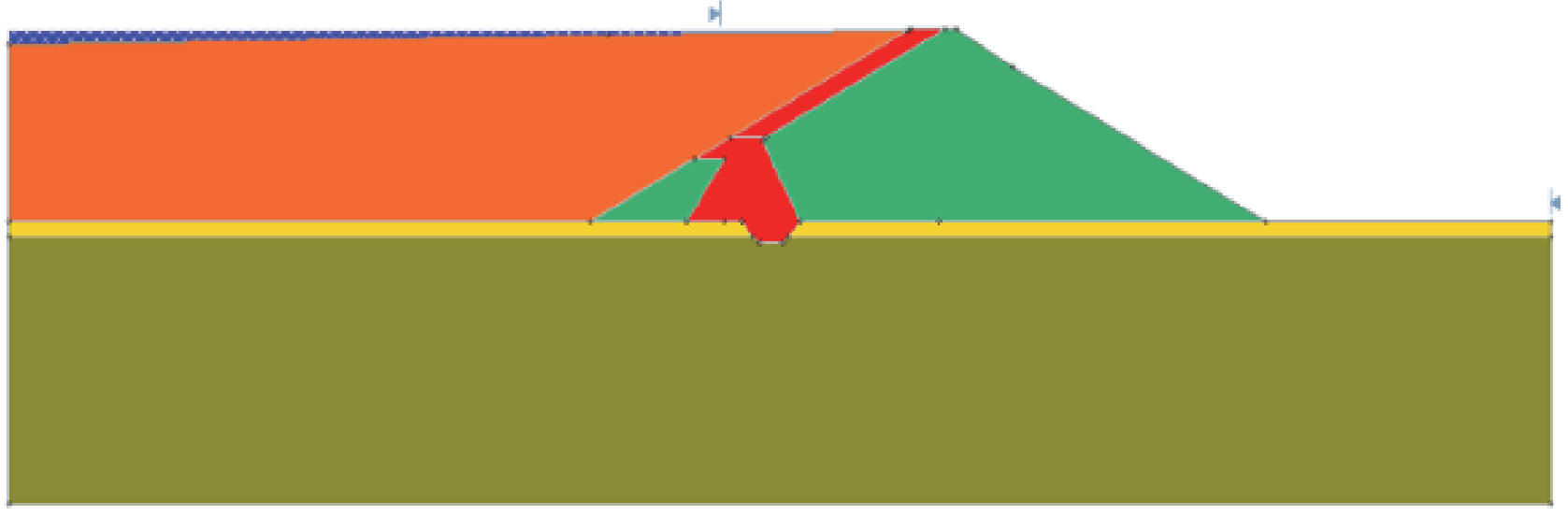

Figure 6 Example 3 geotechnical model and material types (vertical scale exaggerated)

Table 5 Probabilistic inputs for example 3

\begin{tabular}{lllll}
\hline Name & Property & Distribution & Mean & Std. dev. \\
\hline Zone A & Unsaturated shear strength & Normal & 29 & 0.5 \\
Zone C & Unsaturated shear strength & Normal & 30.75 & 4 \\
\hline
\end{tabular}

The results of the test cases are presented in Table 6 . Figure 7 is included to show the insensitivity of the downstream embankment included in this example to the presence of a loose contractive tailings layer that may have occurred due to poor initial control of tailings deposition and/or decant control. In all cases, the stability of the embankment is found to be relatively insensitive to operational performance.

Table 6 Results of analysis for example 3

\begin{tabular}{llll}
\hline Case & Description & FS & PF (\%) \\
\hline 1 & Design case; 50 m dry beach & 2.51 & 0 \\
2 & Upset operational case; no dry beach & 2.22 & 0 \\
3 & Upset operational case, no dry beach and loose contractive layer present & 2.22 & 0 \\
& due to poor operational control of early deposition & & \\
\hline
\end{tabular}




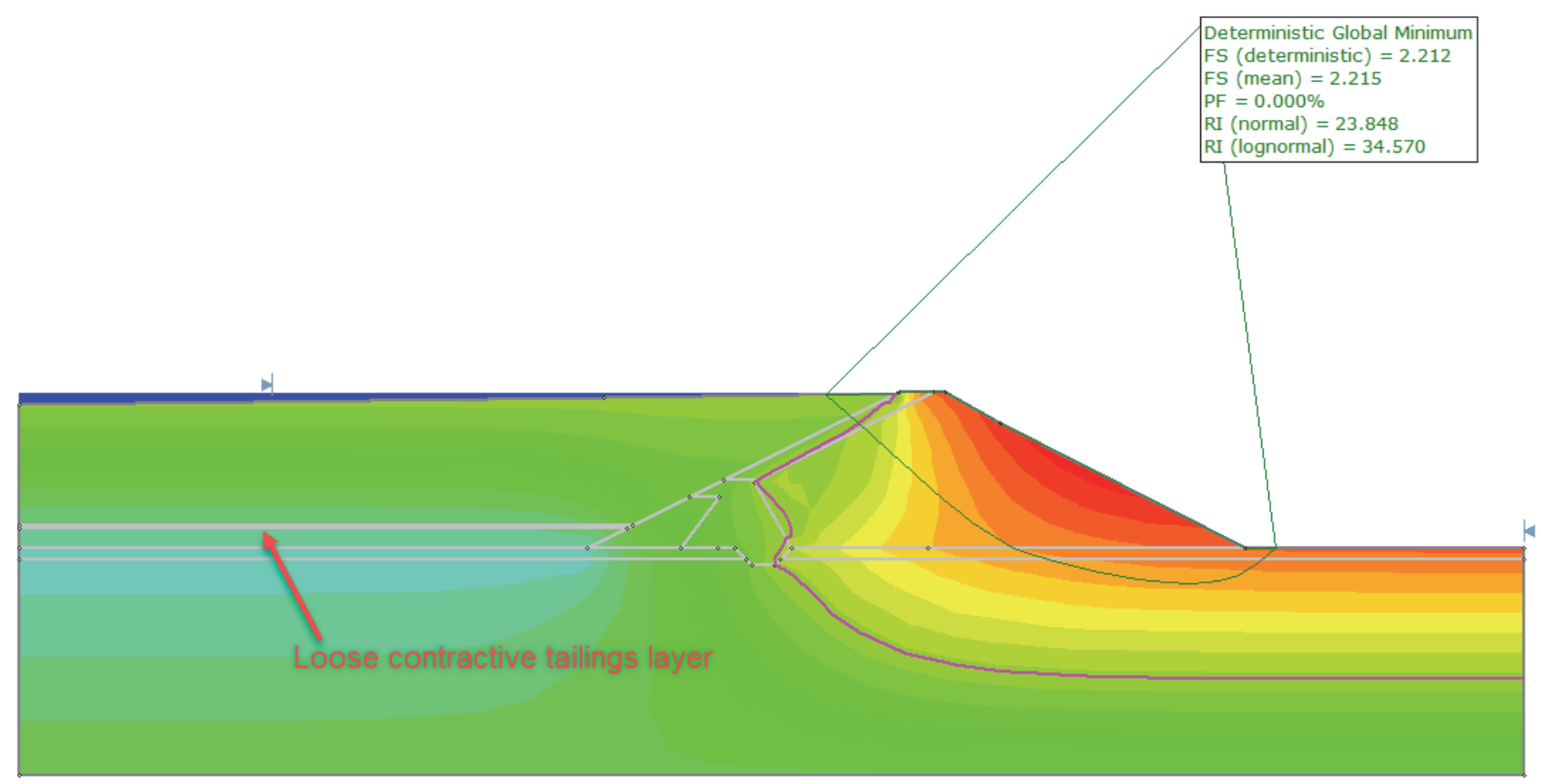

Figure 7 Example 3 embankment with a loose contractive layer of tailings due to poor early operation

\subsection{Example 4: downstream facility constructed from mine waste}

The example 4 embankment is a large downstream raised TSF which is constructed of loosely placed mine waste with a crest width of $70 \mathrm{~m}$ and a maximum height of $10 \mathrm{~m}$. The mine waste is potentially contractive and as such is modelled with an undrained shear strength in saturated zones. This can be seen, along with the material inputs and geometry of the model in Figures 8 and 9. Probabilistic inputs are presented in Table 7. The operational control tested is compliant to a design freeboard of $0.5 \mathrm{~m}$ minimum.

\begin{tabular}{|c|c|c|c|c|c|c|c|c|}
\hline \multirow[b]{2}{*}{ Material Name } & \multirow[b]{2}{*}{ Color } & \multirow[b]{2}{*}{$\begin{array}{l}\text { Unit Weight } \\
(\mathrm{kN} / \mathrm{m} 3)\end{array}$} & \multirow[b]{2}{*}{$\begin{array}{l}\text { Shear Normal } \\
\text { Function }\end{array}$} & \multirow{2}{*}{$\begin{array}{c}\text { Vertical } \\
\text { Strength } \\
\text { Ratio }\end{array}$} & \multirow[b]{2}{*}{$\begin{array}{l}\text { Minimum Shear } \\
\text { Strength (kPa) }\end{array}$} & \multirow[b]{2}{*}{$\mathrm{KS}(\mathrm{m} / \mathrm{s})$} & \multirow[b]{2}{*}{ K2/K1 } & \multirow[b]{2}{*}{$\begin{array}{l}\text { K1 Angle } \\
\text { (deg) }\end{array}$} \\
\hline & & & & & & & & \\
\hline Saturated Contractive Embankment Fill & $\square$ & 25 & & 0.3 & 0 & $1.16 \mathrm{e}-07$ & 1 & 0 \\
\hline Unsaturated Embankment Fill & ᄂ & 25 & Unsat waste & & & $1.16 \mathrm{e}-07$ & 1 & 0 \\
\hline Clayey LGC Material & ए & 18 & User Defined 2 & & & $5.79 e-06$ & 1 & 0 \\
\hline Waste Fines & & 20 & & 0.05 & 0 & $1.16 \mathrm{e}-08$ & 0.1 & 90 \\
\hline
\end{tabular}

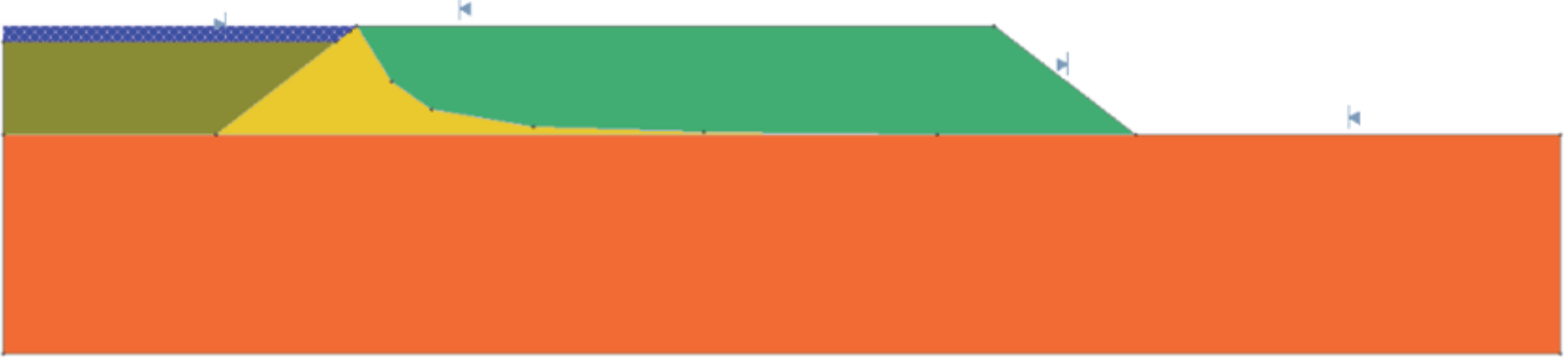

Figure 8 Example 4 geotechnical model and material types (vertical scale exaggerated) 


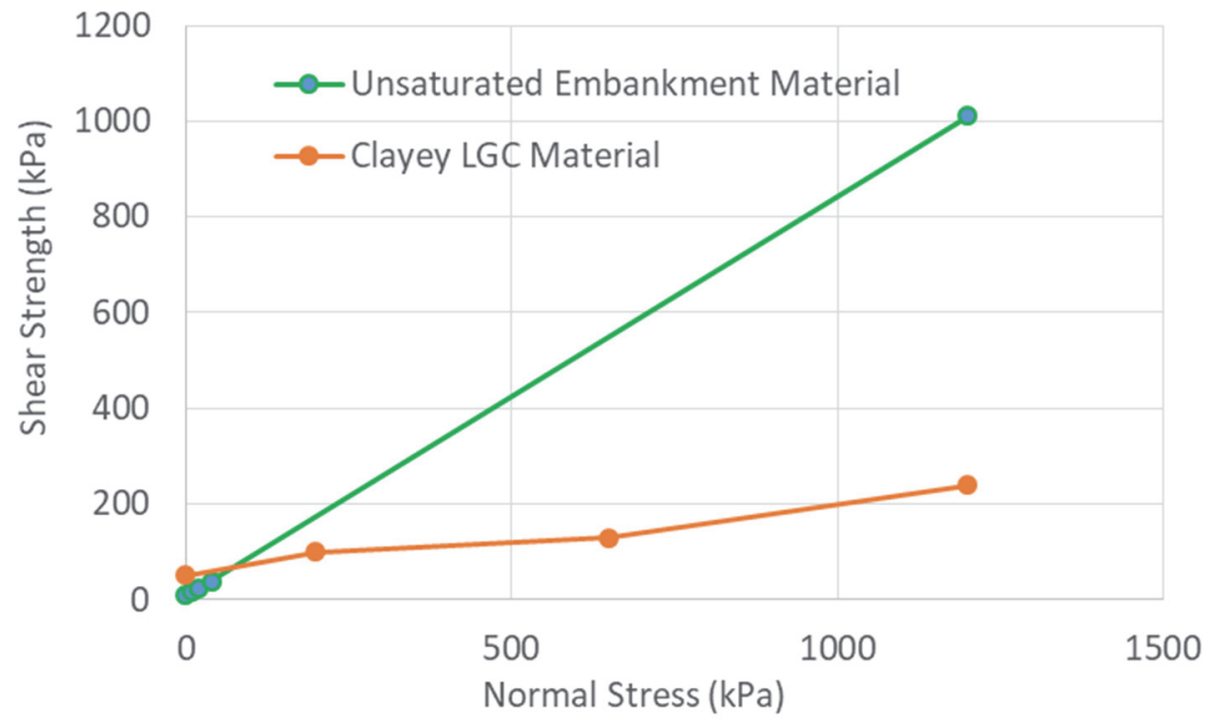

Figure 9 Shear normal functions inputted to example 4 stability modelling

Table 7 Probabilistic inputs for Example 4

\begin{tabular}{lllll}
\hline Name & Property & Distribution & Mean & Std.dev. \\
\hline Saturated contractive embankment fill & Vertical stress ratio & Normal & 0.3 & 0.05 \\
Unsaturated embankment fill & Unsaturated shear strength & Normal & 40 & 3 \\
\hline
\end{tabular}

The results of the cases tested are presented in Table 8, from which it is clear that the embankments global stability is not sensitive to the level of the pond on top of the tailings beach.

Table 8 Results of analysis for example 4

\begin{tabular}{llll}
\hline Case & Description & FS & PF (\%) \\
\hline 1 & Design case; 0.5 m freeboard & 1.98 & 0 \\
2 & Upset operational case; no freeboard & 1.98 & 0 \\
\hline
\end{tabular}

\section{Discussion}

An examination of the sensitivity of different TSF construction methods has been undertaken. The results suggest that downstream raised TSFs (examples 2, 3 and 4) assessed are quite resilient to pond and seepage management measures. However, the downstream facilities (examples 2, 3 and 4) that are analysed in this paper may be more conservatively designed than example 1, based on the FS found for the design cases. In contrast, upstream raised facilities (example 1) appear to be more sensitive to the success of operational controls, which were represented by dry beach width and function of the facility's underdrain in example 1. Further, the TSF in example 1 appears to be quite sensitive to the position of the phreatic surface in the context of the loose contractive layer of tailings, which may have arisen due to poor control of the plant, deposition or decant earlier in the operation of the facility. The presence of the contractive layer in example 1 is similar to the situation reported by Morgenstern et al. (2016) in the Fundal TSF failure. Quite common operational controls could have been introduced to avoid this situation arising, including increased frequency or visual inspection, clear limits on the pond extent (which can be aided by visual markers placed within/around the TSF) and maintaining an operational decant. This result suggests that the stability of upstream raised TSFs is sensitive not only to the adherence to operational controls at the current point in time, but also in the facility's past. Consequently, example 1 demonstrates, in the context of Equation 4, the ability of the owner/operator of a TSF is dependent on the shear strength of tailings which significantly 
influences the PF of the structure. Such sensitivity of the PF is not evident for the other examples, which suggests the owner should consider which controls it considers to be reliable and who takes ownership of these controls. In most cases, the battery limits the engineer of record to exclude the inputs required for the thickener to function, with that responsibility assigned to the owner as mentioned in Geoprofessional Business Association (2018), and, therefore, they may not be aware of the variability that the thickener may have or the control logic it has been programmed to achieve. If detailed operational controls that are able to be stringently employed are not able to be guaranteed, then the choice of an upstream raised TSF design, or any other that relies on the shear strength of tailings for stability purposes, should be carefully considered against the owners risk tolerance prior to construction. However, the potential for a catastrophic failure demonstrated in case 3 of example 1 could still have been avoided by sound investigation of the tailings for subsequent raises. If this had occurred, plans for further raises could have been abandoned or the operational controls could have been modified to ensure the phreatic surface could not extend to or above the contractive layer.

In the case of example 1, the only options during design of the later raises would be to ensure the pond is maintained sufficiently far from the embankment, which would be further aided by the operation of the underdrain, or introduce some other means to drain the beach. Similar to the discussion above, this highlights the reliance of upstream raised TSFs on operation controls as neither of these options can be employed during the design phase. By comparison, the FS and/or PF of example 2 and 4 are highly unlikely to be influenced by the operational controls related to the creation of potentially contractive tailings layers as the critical failure surface (i.e. $F S=1.5$ ) does not extend to the tailings mass and so the tailings shear strength has limited or no influence on the FS and PF. To support this, additional analysis of example 3 was undertaken with a loose contractive layer at $2 \mathrm{~m}$ depth from the tailings beach level was completed, which resulted in negligible impact on the FS and PF. This was likely because the destabilising forces would be relatively low owing to a shallow, flat failure surface. This does not mean that a critical failure surface following a shallow loose contractive layer of tailings is not possible for other TSFs.

A comparison of the influence of similar controls with the use of different construction methods can also be made from the examples presented. Example 1 shows the upstream raised TSF to be relatively insensitive to the operation of the underdrain. Conversely, example 2 is relatively sensitive to the operation of the downstream filter blanket. In both cases, the drains could be considered secondary controls for the location of the phreatic surface after the width of the dry beach and the low-permeability core in example 2 . In contrast to the relative sensitivity of the two examples to operational conditions, the loss of the function of the drain in example 2 has a greater impact on embankment stability. This highlights that specific controls should be understood in the context in which they are being applied. For example, if the example 2 embankment was proposed to be built to provide storage after the TSF in example 1 had reached capacity, it is important that the owner understand that the function of the filter blanket is important, which may not be the impression if the underdrain in example 1 had ceased operating some years ago with little impact on the stability of the facility. Further, to truly appreciate the risk associated with the filter blanket as a design element, the likelihood of failure of the drains should be understood. The underdrain in example 1 is progressively submerged in wet tailings, whereas the filter blanket in example 2 should have a similar reliability as the equivalent in a water dam. Consequently, engineering judgement would suggest that the operational life, and reliability, of the filter blanket should be higher. Following such a process to understand the risk exposure due to the inclusion of these design elements is the starting point of an effective riskinformed design process.

Operational controls can still have a significant impact on downstream raised facilities, especially when the material most influencing embankment stability is located in the foundation and rely on undrained shear strengths. This situation is further worsened by saturation or the application of larger hydrostatic pressures by deposition of tailings and/or maintaining a large decant pond. An example of this is the Mount Polley failure, where the presence of high pore pressures due to a high pond elevation also impacted slope stability (Morgenstern et al. 2015). Although it would not have been possible at Mount Polley, due to a natural 
groundwater level above the clay layer, consider if through sound deposition and decant pond management the clay layer could have been in an unsaturated state.

This discussion highlights the importance of the owner having input early in the design phase by undertaking a risk-informed design approach to inform both parties of the construction method and tolerable risk exposure for the facility. In reference to Equation 4, the owner may seek to minimise capital expenditure and so opt for an upstream raised facility, in which case they may need to accept higher operational expenditure in an attempt to achieve a risk exposure that could have resulted from options requiring greater capital expenditure. In the context of the different construction methods presented in this paper, the other extreme would be to construct a water-retaining structure such as example 2. Alternatively, if the owner is developing a greenfield site and has integrated planning for the storage of waste rock with tailings, an opportunity may exist to construct a conservatively designed structure such as example 4. Such a structure is likely to be insensitive to operational controls and may also be a cost-effective capital solution due to integration within the mine plan allowing the use of mine fleet for construction. However, regardless of the construction method, the use of the theory presented in Equation 4 requires an iterative design procedure between the owner and designer to achieve an acceptable risk exposure of the TSF across its lifetime.

Where a TSF is found to be unacceptably sensitive to the assumed operating condition or operating controls, there are various options available to maintain the same risk exposure (represented by the PF only in this paper) achieved during the design:

\section{Apply greater rigor to operational controls.}

2. Add more, effective operational controls.

3. Modify the design assumptions, where the timing of the project allows.

With regard to example 1 , if the sensitivity of the TSF to operational pond control was understood and determined to be unacceptable, a few options to manage the risk would be available. Perhaps the most robust control would be to modify the design inputs related to the boundary conditions and assumptions associated with the serviceable life of the underdrain prior to clogging occurring. If this option was available, it would lessen the required reliability of operational controls. Alternatively, additional operational controls could be introduced to ensure that the pond is maintained with the $100 \mathrm{~m}$ dry beach assumed. Examples may include procuring a standby decant pump and more frequent inspection of the ponds location so that the duration of any upset period is reduced. If these two controls are not possible, then additional rigor could be applied to maintain the controls that are proposed to ensure, as far as practical, the operational controls are maintained. 'Additional rigor' often takes the form of more administrative checks to ensure that controls are effective but other options include automated monitoring and management systems that increase the likelihood that key controls are tracked regularly by reducing or eliminating the human element.

The controls incorporated into case 1 for each example are typical for regulatory compliance in various jurisdictions, specifically for minimum operating freeboard. In nearly all cases examined, it is clear that compliance with these requirements does not ensure a sound understanding of the risk posed by a TSF. Further, it does not guarantee satisfactory performance or achieving a design within the owner's risk tolerance, as achieving compliance does not require consideration or testing of the operational controls assumed in the design. The approach presented could assist the TSF owner in achieving a tolerable risk exposure.

\section{Conclusion}

It is hoped that the examples provided in this paper have illustrated the importance of employing a realistic operational strategy and assurance process whilst designing a TSF in order to ensure a robust design. The boundary conditions and/or assumptions applied to the design may have a significant impact on the PF. Therefore, engagement between the owner and designer is required, as simply meeting regulatory compliance for the operation of a TSF may not necessarily ensure the risk posed by the facility is within the owner's risk tolerance. Despite a design complying with regulatory requirements and industry norms, the 
creation of unachievable operational controls could occur and, as such, the risk during the operational phase may exceed that accepted during the design phase. Consequently, if the owner is not involved during the design, they may only appreciate the risk posed by the facility after an upset condition has arisen during operation. If this situation occurs, it may be too late for all business objectives, such as maintaining operation of the processing plant, to be met. For example, plant output may have to be reduced to allow a large pond to be reduced or mining may have to move to an area with a higher strip ratio to access a higher grade ore in order to reduce tailings production to delay the filling of an operating TSF until a new facility can be constructed. In contrast, the lack of owner engagement could also result in conservative design that meets the owner's risk tolerance, but requires relatively high capital expenditure.

If the owner is engaged at the start of the design process to agree on the assumptions relating to operation, monitoring and maintenance of the TSF, these assumptions can then easily be transferred into objectives for operation as captured in the TSF's operating manual. In turn, achieving these objectives can be aided by the implementation of effective controls. The controls should be reflected in the operating manual and the management structure employed by the owner.

For the example cases tested in this paper, TSFs that do not rely upon the shear strength of previously deposited tailings have been shown to be significantly more resilient to the failure of common operational controls than TSFs that do rely on the strength of previously deposited tailings. However, all TSFs are unique structures and this conclusion is drawn from a very limited sample size and so the designer and owners of TSFs should complete their own analysis in this regard.

Examples 3 and 4 demonstrate that the PF of downstream raised TSFs that have been somewhat conservatively designed are insensitive to operational controls. If the approach suggested in this paper was followed, it would allow the capital cost of TSF construction to be balanced with other business objectives, including risk exposure.

\section{References}

Australian National Committee on Large Dams 2012, Guidelines on Tailings Dams - Planning, Design, Construction, Operation and Closure, Australian National Committee on Large Dams, Hobart.

Boshoff, J 2015, 'Responsible tailings management', Proceedings of Tailings and Mine Waste Management for the 21st Century, The Australasian Institute of Mining and Metallurgy, Melbourne.

Bruce, IG \& Oboni, F 2002, 'Risk-management process for tailings control', Mining Engineering, vol. 54, no. 10, pp. $14-17$.

Duncan, JM 2000, 'Factors of safety and reliability in geotechnical design', Journal of Geotechnical and Geoenvironmental Engineering, pp. 307-316.

Geoprofessional Business Association 2018, Proposed Best Practices for the Engineer of Record (EOR) For Dams, Geoprofessional Business Association

International Committee on Large Dams 2001, Bulletin 121: Tailings Dams: Risk of Dangerous Occurrences: Lessons Learnt from Practical Experiences, International Committee on Large Dams, Paris.

ICMM 2016, Preventing Catastrophic Failure of Tailings Storage Facilities, ICMM, London.

Martin, TE \& Davies, MP 2002, Trends in the Stewardship of Tailings Dams, AGRA Earth \& Environmental Limited, Burnaby.

The Mining Association of Canada 2017, A Guide to the Management of Tailings Facilities, 3rd edn, The Mining Association of Canada, Ottawa.

Morgenstern, NR, Vick, SG \& Van Zyl, D 2015, Independent Expert Engineering Investigation and Review Panel: Report on Mount Polley Tailings Storage Facility Breach, viewed 7 February 2019, https://www.mountpolleyreviewpanel.ca/final-report

Morgenstern, NR, Vick, SG, Viotti, CB \& Watts, BD 2016, Fundão Tailings Dam Review Panel: Report on the Immediate Causes of the Failure of the Fundão Dam, viewed 7 February 2019, http://fundaoinvestigation.com/wp-content/uploads/general/PR/en/ FinalReport.pdf

Murray, L, McLeod, H \& Suter, G 2010, 'Effectiveness in risk assessment - a comparison of perceived and realised risk from project concept to construction and operation', in AB Fourie \& RJ Jewell (eds), Proceedings of the First International Seminar on the Reduction of Risk in the Management of Tailings and Mine Waste, Australian Centre for Geomechanics, Perth, pp. 217-228.

Rocscience Inc. 2017, Slide, version 7.0, computer software, Rocscience Inc., Toronto.

US Department of the Interior Bureau of Reclamation 2015, Best Practice in Dam and Levee Safety Risk Analysis, US Department of the Interior Bureau of Reclamation, Washington DC. 
